

\title{
Eco-designed Conformable Inorganic Electronics to Improve the End of Life of Smart Objects: Sensor Processing and Applications
}

Maxime Harnois, Fatima Garcia-Castro, Gaëtan Herry, Olivier De Sagazan, France Le Bihan

\section{To cite this version:}

Maxime Harnois, Fatima Garcia-Castro, Gaëtan Herry, Olivier De Sagazan, France Le Bihan. Ecodesigned Conformable Inorganic Electronics to Improve the End of Life of Smart Objects: Sensor Processing and Applications. ACS Applied Electronic Materials, 2020, 2 (2), pp.563-570. 10.1021/acsaelm.9b00807 . hal-02651031

\section{HAL Id: hal-02651031 \\ https://hal-univ-rennes1.archives-ouvertes.fr/hal-02651031}

Submitted on 4 Jun 2020

HAL is a multi-disciplinary open access archive for the deposit and dissemination of scientific research documents, whether they are published or not. The documents may come from teaching and research institutions in France or abroad, or from public or private research centers.
L'archive ouverte pluridisciplinaire HAL, est destinée au dépôt et à la diffusion de documents scientifiques de niveau recherche, publiés ou non, émanant des établissements d'enseignement et de recherche français ou étrangers, des laboratoires publics ou privés. 


\title{
Eco-designed conformable Inorganic Electronics to Improve the Smart Object End of Life: sensor's
} processing and applications. Maxime Harnois*, Fatima Garcia Castro, Gaëtan Herry, Olivier De Sagazan, France Le Bihan

Université Rennes 1, Institut d'Électronique et des Télécommunications de Rennes, UMR CNRS 6164, Département Microélectronique \& Microcapteurs, Campus de Beaulieu, 35042 Rennes Cedex, France

KEYWORDS: Inorganic strain sensors; Conformable Electronics; Water Soluble Electronics; WEEE Standard; Ecodesigned Electronics.

\begin{abstract}
.
The plastic pollution is indisputable and technologies aiming to add flexible electronics onto objects have to take into consideration such environmental issue. Faced with this challenge, the development of technologies that comply with current standards such as WEEE (Waste Electric and Electronic Equipment) legislation is crucial. Green electronics based on fully biodegradable
\end{abstract}


materials is under development but needs time to be put on the market. Meanwhile, inorganic electronic remains a good candidate. Consequently, it makes sense to transfer inorganic electronics onto objects before it dismantling and recoveries.

Here, an eco-designed technology allowing the transfer of electronics onto objects is detailed. Silicon-based devices are transferred from polyimide substrate (PI) to water-soluble substrate (PVA: Poly(vinyl alcohol)). It is highlighted that the transfer of inorganic layers from PI to PVA substrate does not have a negative impact on the devices mechanical and electrical characteristics. To demonstrate such concept, strain gauges and temperature sensors have been transferred onto daily life object reaching the same performances than sensors fabricated onto polyimide substrate. Moreover, materials transferred onto the object using PVA substrate can be dismantled and recovered at the end of object's life highlighting that hydrosoluble substrate is a good candidate towards an eco-designed technology.

\section{Introduction}

High-tech products are becoming essential in our daily life promoting a constant growth of the electronic industry. Thus, the everyday objects are smarter and smarter as embedded electronics giving them extra functionalities. ${ }^{1}$ However, our new consumption needs must not be done, once again, at the expense of the environment. Faced with this challenge, Extended Producer Responsibility (EPR) principle has been established by the Organization for Economic Cooperation and Development (OECD). ${ }^{2}$ This is a cornerstone 
principle of waste prevention and reduction policy. The basic idea of EPR is to hold producers responsible for the environmental impact of their products at the end of life pushing them to change their practices towards the eco-design (also called design for environment activities) and the respect of the Waste Electric and Electronic Equipment (WEEE) legislation (Directive 2002/96/EC of the European Parliament and of the Council). ${ }^{3,4}$ Consequently, eco-designed fabrication processes taking into consideration the smart object end of life should be developed to respect the WEEE legislation. Up to know, this aspect is overlooked in works dealing with novel technologies development especially in the field of new generation of electronics such as "plastic electronics".

In the near future, connected objects will embed sensors, ${ }^{5,6}$ displays, ${ }^{7,8}$ photovoltaic panels, ${ }^{9,10}$ antennas, ${ }^{11,12}$ etc. not only into but also at the surface of the object. Among technologies developed to intimately wrap electronics onto 3D objects, those using polymeric substrates (flexible or even stretchable) are frequently reported. This last 15 years, research has focused on materials and methods to improve devices performances and conformability instead of environmental concerns or even circular economy. Indeed, 
original concepts have been developed such as ultrathin electronics, ${ }^{9,13}$ stretchable electronics ${ }^{14-17}$ or even thermoforming technologies. ${ }^{18}$ However, polymeric substrates (e.g., polyimide: PI, Polyethylene terephthalate: PET, Polyethylene naphthalate: PEN, parylene, polydimethylsiloxane: PDMS ...) are permanently stuck onto the 3D object that negatively impact Electric and Electronic Equipment (EEE) recycling.

Recently, a number of biodegradable polymers, e.g. cellulose, chitin, silk, etc. have been considered as substrates for environmental concerns or even for the fabrication of implantable electronics, piezoelectric energy harvester. ${ }^{19-23}$ Biodegradable substrates can lead to the same results in term of conformability than classical polymeric substrate however they are not compatible with clean room processing (e.g., the photolithography or the wet etching steps). To overcome this challenge, novel fabrication methodologies have to be developed. ${ }^{24}$

Here, a comparative study between inorganic strain sensors fabricated onto polyimide substrate and water soluble substrate is detailed. It will be shown that the process developed to transfer the inorganic layer from PI to PVA substrate Poly(vinyl alcohol) did not have a negative impact on the devices electrical characteristics. Note that, the process described in this work cannot be considered as eco-friendly because it meets all the perquisites of standard cleanroom 
manufacturing (chemical etching, photolithography, etc.) and can be transferred to the industry (contrary to green electronics, to date). However, the concept describes in the last section can be considered as eco-designed because it will highlights that hydrosoluble substrate is a good candidate facing smart object recycling issues because inorganic devices can be unmounted from the object surface to be recovered.

\section{Results and Discussion}

\section{a. Inorganic processing onto hydro-soluble substrate}

The figure 1 highlights the fabrication process of multilayered devices transferred onto a PVA substrate. The process is fully compatible with cleanroom fabrication even if the targeted substrate is water soluble. Experimental parameters are fully detailed in the experimental section. As shown in figure 1a, at first, a PDMS layer was spin coated on a silicon carrier substrate and cured. A $25 \mu \mathrm{m}$ thick polyimide (PI) substrate was laminated onto the PDMS (figure $1 \mathrm{~b}$ ). The adhesion forces between PDMS and PI are strong enough to provide a good sticking during the whole process. The 3D scheme in the figure 1c shows that multilayered thin films can be deposited and patterned at lithographical accuracy. Here, resistors made of two inorganic layers were fabricated. Electrodes and resistive layers were made of aluminum and silicon, respectively. As shown in the figure 1d, the PVA solution was spin coated following the protocol already described in a previous work. ${ }^{17}$ As a results, the inorganic devices were sandwiched between the PI and the PVA layers (figure 1e). The total thickness of the structure was approximately equaled $55 \mu \mathrm{m}$ and was flexible. The multilayered flexible substrate can be easily peeled off from the PDMS and flipped on it. Thus, the PVA substrate adheres to the PDMS. Indeed, PDMS is well known to adheres to many 
kind of surfaces as it is extensively used in microfluidics for instance. ${ }^{25}$ Note that, the PDMS substrate can be reused from one process to another. The last stage consists in the dry etching of the PI films using $\mathrm{O}_{2}$ plasma. After PI films fully-etching, the inorganic devices was transferred to the PVA substrate as shown in the 3D schemes of figure $1 \mathrm{~g}$ and in the optical pictures of the figures 1h and $1 \mathrm{i}$.

The figure $1 \mathrm{k}$ highlights the time sequence of the PVA substrate dissolution. Note that, in the figure 1h, a PI ring remains after dry etching of the PI substrate. This etching residue is due to the mechanical clamp used to fix the wafer during the etching stage. The top left image of the figure $1 \mathrm{k}$ highlights that a part of the flexible substrate is composed of a PVA film (transparent area) as substrate and a sandwich of PVA and PI (i.e., the dark yellow etching residue). In the figure 1k, after approximately 90 seconds, The PVA substrate was fully dissolved in water whereas the PI substrate was intact with inorganic material remaining on it. Consequently, the fabrication process does not damaged the PVA substrate and especially it ability to be dissolved in water. Consequently, the fabrication process described here clearly highlights that it is possible to fabricate multi-layered based inorganic devices onto PVA substrate without suffering from drawbacks inherent to the nature of PVA. Indeed, even if water based chemical agent or incompatible processing temperature $\left(>150^{\circ} \mathrm{C}\right)$ are used onto PI substrate, it does not affect the capabilities of PVA substrate.

\section{b. Inorganic strain sensor}

Inorganic strain sensors were fabricated on two kinds of substrates: a $25 \mu \mathrm{m}$ thick Poliymide and a $30 \mu \mathrm{m}$ thick PVA substrate. As shown in Figure 2, their response to mechanical strain were analyzed in static (as function of bending radius) and dynamic 
modes (voltage and resistivity as function of time and applied strain). In static mode (figures $2 \mathrm{a}, 2 \mathrm{~b}$ and $2 \mathrm{c}$ ), the protocol consists in the measurement of the current as function of the voltage in the range of plus to minus $1 \mathrm{~V}$ when substrate is flat (bending radius equals 0 ). It allows to determine the initial value of the resistivity. Then, the substrates were fixed to a tensile bending tools (half cylinders) and were bent from the lowest curvature (i.e., the lower applied strain) to the highest curvature (i.e., the highest applied strain). The bending radii were fixed to 0 (flat), 2.5 (R1), 2 (R2), 1.5 (R3) and 1 cm (R4).

Then, the gauge factor (GF) is used to qualify the sensitivity of strain sensors fabricated onto the PVA and the PI substrate as shown in figures $2 b$ and $2 c$, respectively. GF is defined by the Equation (1) as the ratio of the relative change of the sensors resistivity $\left(\Delta R / R_{0}\right)$ and the strain capplied to the sensor:

$G F=\frac{\Delta R}{R_{0}} \varepsilon$

For metals, GF is low, between 2 and $5{ }^{26}$ whereas for semiconductors such as silicon, GF exhibits much larger values around 100 for single crystalline silicon (sc-Si), between 
20 and 40 for poly crystalline silicon (poly-Si) ${ }^{27}$ or $20-30$ for amorphous silicon (a-Si) ${ }^{28}$. In this work, microcrystalline silicon is deposited. The SG has already been determined in previous works and is fixed to $80 \mathrm{GPa}{ }^{29}$. Here, the strain $(\varepsilon)$ applied to the structure is function of the radius of curvature. $\varepsilon$ is calculated using the already proposed model for a bi-layer device taking into consideration their thicknesses and their Young modulus $(Y) .{ }^{29}$ In this work, the material properties and device structure are presented in the figure 1 and the Table S1 of the supporting information. This model takes into account the substrate and the stiffest layer (i.e. the silicon), which mainly define the mechanical behavior of the device. Consequently, the bilayer model is thus constituted by the PI substrate and the Si layer and the longitudinal strain Esurface applied on the surface of the layer is given by the equation (2) derived from [25]:

$\varepsilon_{\text {surface }}=\left(\frac{1}{r} \pm \frac{1}{r_{0}}\right)\left(\frac{d_{s}+d_{f}}{2}\right)\left(\frac{1+2 \chi \eta+\chi \eta^{2}}{(1+\eta)(1+\chi \eta)}\right)$ 
where $r$ and $r_{0}$ are the applied and initial radii of curvature, respectively, $d_{S}$ and $d_{f}$ are substrate and layer thicknesses, respectively, and are defined by $\chi=Y_{f} / Y_{S}$ and $\eta=d_{f} / d_{S}$, where $Y_{S}$ and $Y_{f}$ are substrate and layer Young modulii, respectively. The plus (or minus) signs depends on applied bending opposite to (or with) the built-in curvature. The silicon, the PI and the PVA thicknesses were measured and were equaled $100 \mathrm{~nm}, 25 \mu \mathrm{m}$ and $30 \mu \mathrm{m}$, respectively. To calculate the strain, the young modulus of the PI and the PVA substrates have been fixed to $5 \mathrm{GPa}{ }^{30}$ and $1.9 \mathrm{GPa}$, respectively, according to the literature. ${ }^{16}$

Figures $2 b$ and $2 c$ show that $S G$ values equal -21 and -24 for sensors fabricated onto PVA and PI, respectively. It can be notice that the collected data points (see in figure $2 \mathrm{~b}$ ) corresponding to the highest strain value has not been taken into consideration in the calculation of GF. Indeed, as shown in figure S1, when the strain exceeds approximately $0.14 \%$ cracks occur in the silicon layer leading to drastically increases the strain sensors resistivity. An option to decrease the strain is to reduce the substrate thickness $\left(d_{s}\right)$. Indeed, as shown in figures $2 \mathrm{~b}$ and $2 \mathrm{~d}$, at same radius of curvature, the applied strain in 
$\mathrm{PI}$ is lower than the applied strain in PVA mainly because the PVA substrate was $5 \mu \mathrm{m}$ thicker than the PI substrates. However, it is demonstrated that the sensitivity and the mechanical behavior of the strain sensors is in the same order of magnitude proving that the fabrication process does not impact the strain sensors response.

As shown in the figures $2 \mathrm{~d}, 2 \mathrm{e}$ and $2 \mathrm{f}$, the strain sensors have been mounted onto a rubber based membrane submitted to a differential pressure (see also in the supplementary figure S2). Each 5 seconds, a pulse of 900 mbar is applied onto the membrane that deforms the sensors (Elveflow pressure controller; MK3). The value of the sensor resistivity is recorded, amplified and converted in voltage using analogic circuits in combination with Arduino Uno development Kit.

The variation of the voltage as function of time is plotted in the figures $2 \mathrm{e}$ and $2 \mathrm{f}$. It highlights that whatever the substrate a signal can be recorded showing a good response of the sensors in dynamic mode. Finally, sensors have been mounted onto the finger joint of a nitrile glove. The variation of the resistivity as function of the finger motion is recorded and shown in the figures $2 \mathrm{~g}, 2 \mathrm{~h}$ and $2 \mathrm{i}$. These experiments highlight that inorganic strain 
gauge fabricated onto PVA substrate can be used as sensors for prosthetic hands has already demonstrated for these fabricated onto other plastic substrates. ${ }^{31-33}$ However, the main difference can rely on the WEEE management of such devices has demonstrated in the next section.

\section{c. WEEE management}

On the one hand, significant challenges in the management of WEEE are the dismantling and the recovery of materials. ${ }^{34}$ On the other hand, it can be anticipated that most of our future products will embed electronics. For instance, daily life objects such as a T-Shirt that will embed sensors or RFID Tag will be not considered as a T-shirt from recycling point of view, but as a WEEE. Consequently, the objects' end of life must be taken into consideration when a new technology is developed in order to respect the eco-design rules already fixed by the legislation. It is the case of flexible electronics, the results detailed in the previous section and in the literature have demonstrated that plastic electronics can conformably wrap daily life object. However, the question of the EoL is not taken into consideration. For instance, when plastic foils will be stuck onto the object, can the electronics devices be separated easily from the object? Furthermore, when 
devices are fabricated onto conventional plastics such as PI substrates, is device's materials can be dismantled from the substrate? From recovery point of view, some of most interesting materials are metals. Is it possible to recovery the pure metals and reuse them as high grade electronics materials? In future works, these questions cannot be avoid and need to be systematically taken into consideration.

This section highlights that the technology based on water soluble substrate to transfer inorganic devices onto daily life objects fits the requirement of the WEEE legislation as materials can be recovered. Moreover, the daily life object can be reused. To take benefit from PVA as sacrificial layer from WEEE recycling point of view, resistive inorganic temperature sensors have been conformably wrapped onto a daily life object (a cup). The following experiments illustrate our concept and highlight how inorganic material can be recovered after the object lifecycle.

The figures $3 a, 3 b$ and $3 c$ show the daily life object (a cup), inorganic resistors fabricated onto PVA substrate and the devices transferred onto an edge of the cup, respectively. Different technologies based on the concept of water assisted transfer can be used to 
provide a conformal wrapping of devices onto an object. All benefit from water to partially or fully dissolve the hydrosoluble substrate to transfer the devices. They are named tattoo electronics, ${ }^{35-37}$ water transfer printing, ${ }^{6,38,39}$ hydroprinting, etc. ${ }^{40}$ Furthermore, previous works have demonstrated that the water transfer printing is a convenient technology to fabricate large area electronics answering industrial issues. ${ }^{41}$ In this work, the external part of the cup has been humidify and the PVA substrate has been stuck to the external wall of the cup. Consequently, has already shown by Rogers et al. the bottom face of the PVA substrate is partially dissolved and conformably adheres to the object. ${ }^{42}$ The figure $3 \mathrm{~d}$ highlights that the resistive temperature sensor is still working after it conformal mounting on the cup. One can notice that the value of the resistance equals $47.2 \mathrm{KOhm}$ that is in the same range than for the experiments in the figure 2. This step can be considered as the testing step of a smart daily life object.

The figure $3 \mathrm{e}$ shows the evolution of the temperature inside (black curve) and in the external part of the cup wall (red curve) when the cup is filled with boiling water and cool down. The temperature inside and outside the wall has been measured using a k-probe thermocouple and an IR-thermometer, respectively. As expected, the two temperatures follow the same trend, and the temperature on the external part of the wall is systematically lower than the temperature inside. 
Furthermore, when the cup is filled with boiling water, the temperature inside the cup grows up faster than this on the external part of the wall cup as also expected. The blue curve shows the variation of the sensor resistivity as function of the temperature. The trend of the blue curve follows the same behavior than the temperature measured using the IR-thermometer showing that the temperature at the surface of a daily life object can be monitored. The figure $3 \mathrm{f}$ highlights the dissolution of PVA when the cup is dipped into the water. It highlights the dismantling of the inorganic layer from the object. Indeed, as shown in the figure 3f, the PVA is fully dissolved after 150 seconds detaching the inorganic devices. Thus, the object and the inorganic materials (after water filtration) can be recovered to be reused as shown in the figures $3 \mathrm{~g}$ and $3 \mathrm{~h}$, respectively. At this step, two alternative can be chosen: object and inorganic materials can be recycled (second life) or destroyed following the WEEE standards. In both cases, this smart object end of life will be improved thanks to the eco-designed technology developed in this work. Moreover, even if silicon based materials remains in water, such inorganic nanomembrane will be fully dissolved as already reported in literature. ${ }^{43,44}$

\section{Conclusion}

Due to harmful aspects of human activity, our Mother Earth is facing environmental concerns. Plastic pollution is one of these environmental issues and the new generation of electronics that will flexible, stretchable, etc. have to take into consideration these issues. Here, a technologies allowing to wrap inorganic devices onto 3D object is reported. In addition to save electrical and mechanical capabilities, devices performed onto water soluble substrate can be dismantled from the object and recovered. Furthermore, it can be anticipated that other eco-friendly materials that can be put into solution can be compatible with the process described in this works. 


\section{Experimental Section}

\section{a. Characterization:}

Top-view images were obtained by PENTAX K70D equipped with a ZOOM macro 50mm (Pentax). Static I(V) electrical characteristics of the devices were collected at room temperature using an Agilent B1500A semiconductor parameter analyzer. Temperature were measured using a Fluke $51 \mathrm{II}$ thermometer using an K-probe (Ohmega) and a Fluke 62 Max IR-thermometer.

\section{b. Fabrication}

PDMS adhesion layer: Sylgard 184 PDMS was purchased from Dow Corning (Midland, U.S.A.), mixed with curing agent at a mass ratio of $10: 1$, and degassed for $30 \mathrm{~min}$ before spin-coating. Spin-coating parameters (velocity $=300 \mathrm{rpm}$; acceleration $=50 \mathrm{rpm} \cdot \mathrm{s}^{-1}$; duration $=60 \mathrm{~s}$ ) were kept constant for all the experiments (i.e., after curing, such spincoating parameters allow the fabrication of $300 \mu \mathrm{m}$ thick PDMS on silicon substrates). 
Polyimide Substrate: A $25 \mu \mathrm{m}$ thick substrate of PI (DuPontTM France) were manually laminated onto the PDMS. Air bubbles trapped between PI and PDMS were removed under vacuum.

PVA processing: a PVA solution (PVA; Mw 9000-10000, 80\% hydrolyzed from Aldrich) was prepared by mixing DI (deionized) water and PVA powder (5:1 w/w water/PVA) and filtering it with a $0.4 \mu \mathrm{m}$ filter. The PVA is filtered to avoid any aggregates. This step allows the fabrication of a PVA surfaces as smooth as possible (nanometric scale).PVA was spin-coated on PI substrates to form a $30-\mu$ m-thick layer and baked at $100^{\circ} \mathrm{C}$ for 2 hours. The spin-coating was performed at low rotation velocity $20 \mathrm{rpm}$ and acceleration $10 \mathrm{rpm}$ s-1 for uniform thickness.

Inorganic Thin film patterning: A 150-nm-thick aluminum film was deposited by thermal evaporation at a deposition rate of $0.2 \mathrm{~nm} \mathrm{~s}-1$. A classical lithographic process using S1818 (Dow electronic material MICROPOSIT) as photoresist (velocity $=4500 \mathrm{rpm}$; acceleration $=5000 \mathrm{rpm} \mathrm{s}-1$; duration $=60 \mathrm{~s})$ was performed to pattern the aluminum electrodes that can be both wet etched (H3PO4) or dry etched in ICP/RIE (inductive 
coupled plasma / reactive ion etching) equipment from Corial (France) with the experimental settings of $5 \mathrm{mTorr}$ working pressure, $100 \mathrm{~W}$ plasma power, and chlorinated gas flow of $30 \mathrm{sccm}$.

A 150-nm-thick silicon film was deposited by PECVD (Plasma Enhanced Chemical Vapor Deposition. Experimental settings were adjusted as follows: The gazes' flow rate are fixed to $1.5 \mathrm{sccm}$ of $\mathrm{SiH} 4,75 \mathrm{sccm}$ of $\mathrm{H} 2$ and $75 \mathrm{sccm}$ of $\mathrm{Ar}(1 \%$ dilution of $\mathrm{SiH} 4$ in $\mathrm{Ar}-\mathrm{H} 2$ mixture), $10 \mathrm{Sccm}$ of AsH3. The working pressure, the power and the temperature equals $0.9 \mathrm{mbar}, 15 \mathrm{~W}$ and $165^{\circ} \mathrm{C}$, respectively. $1.8 \mu \mathrm{m}$ thick of $\mathrm{S} 1818$ was spin-coated (velocity $=4500 \mathrm{rpm}$; acceleration $=5000 \mathrm{rpm} \mathrm{s}-1$; duration $=60 \mathrm{~s})$ and used as mask to define the active area of the resistors. The n-doped Silicon was etched using SF6 plasma (Roth and Roh equipement). The experimental parameters were adjusted as follows: The gaze flow rate is fixed to $50 \mathrm{sccm}$ of $\mathrm{SiH} 4$. The working pressure, the power and the temperature equals $30 \mathrm{mTorr}, 50 \mathrm{~W}$ and $20^{\circ} \mathrm{C}$, respectively.

$P /$ substrate etching: dry etched in ICP/RIE (Corial, France) with the experimental settings of $20 \mathrm{mTorr}$ working pressure, $950 \mathrm{~W}$ and $50 \mathrm{~W}$ for the ICP plasma and the RF power 
respectively, an oxygen and Argon gases flow of $30 \mathrm{sccm} 50 \mathrm{sccm}$ respectively was used to etch the PI film.

\section{Acknowledgments}

This work is supported by the European Union through the European Regional

Development Fund (ERDF), by the French region of Brittany (project: IMPRIM'), and by IETR (project: 3DELEC). 

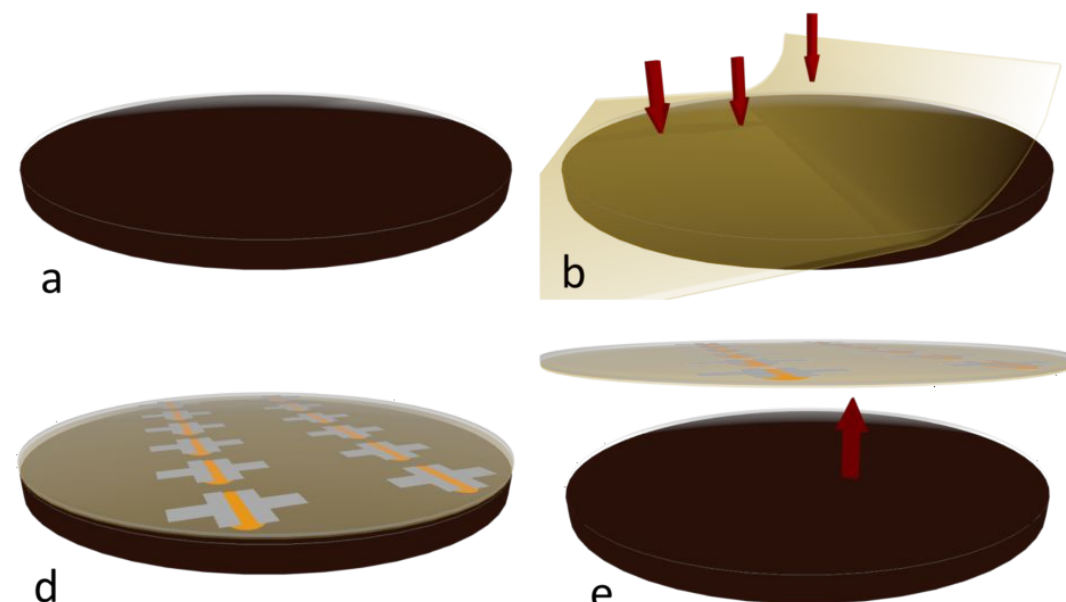

d

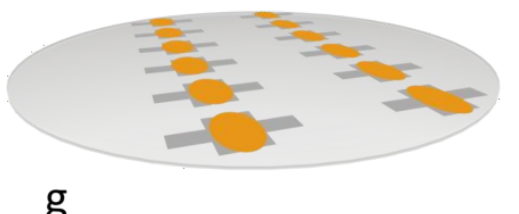

g
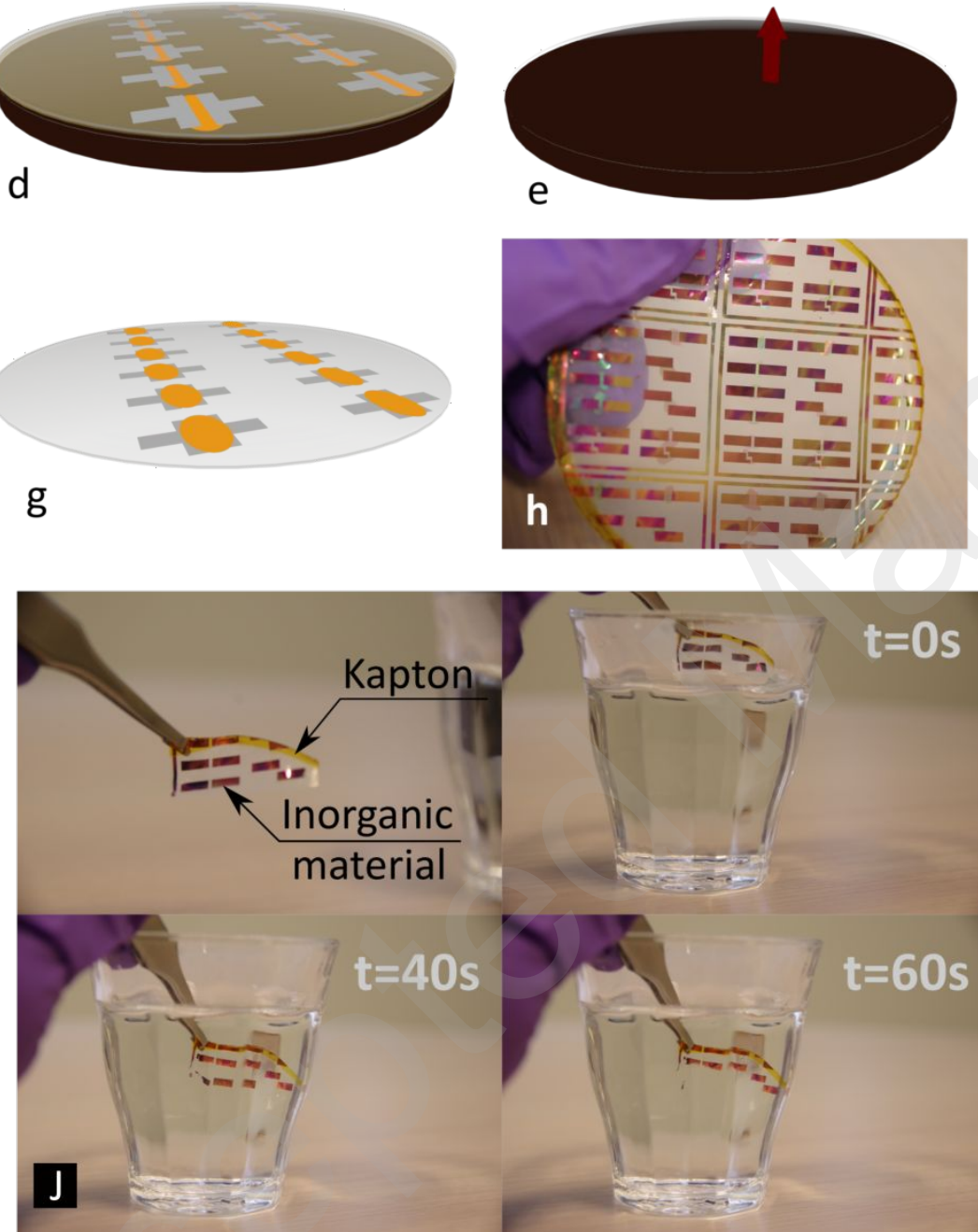
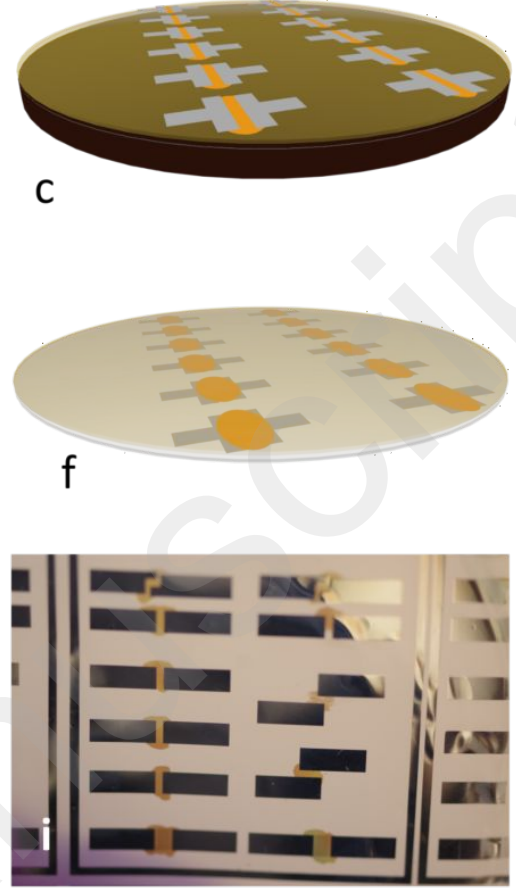

C

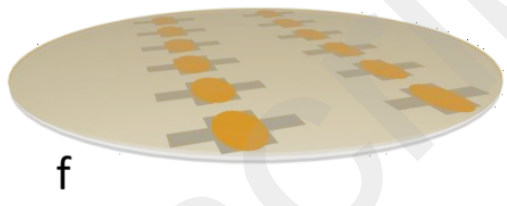

$t=0 s$

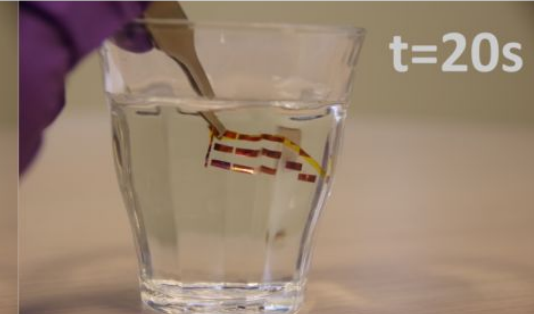

$t=60 s$

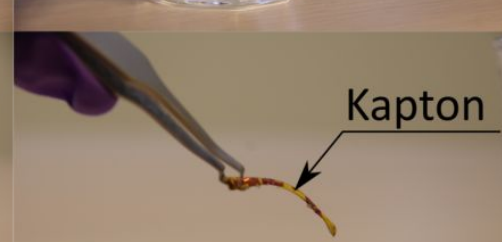

Figure 1. Inorganics multilayered electronics transferred onto PVA substrates. a) PDMS

spincoated onto silicon substrate, b) PI substrate laminated onto PDMS, c) multilayered inorganic thin films patterned onto PI, d) PVA spin coating, e) PI substrates pealing from 
the PDMS adhesive layer, f) Multilayered inorganic devices sandwiched between the PI and the PVA films, g) Inorganics devices transferred to the PVA substrates after dry etching of the PI substrate, h) optical picture after the PI etching; i) zoom in the devices; j) Dissolution of the PVA substrate as function of time; To evaluate quantitatively the dissolution rate of PVA as function of additional external physical parameters such as baking temperature, additional experiments have to be performed."

a



d
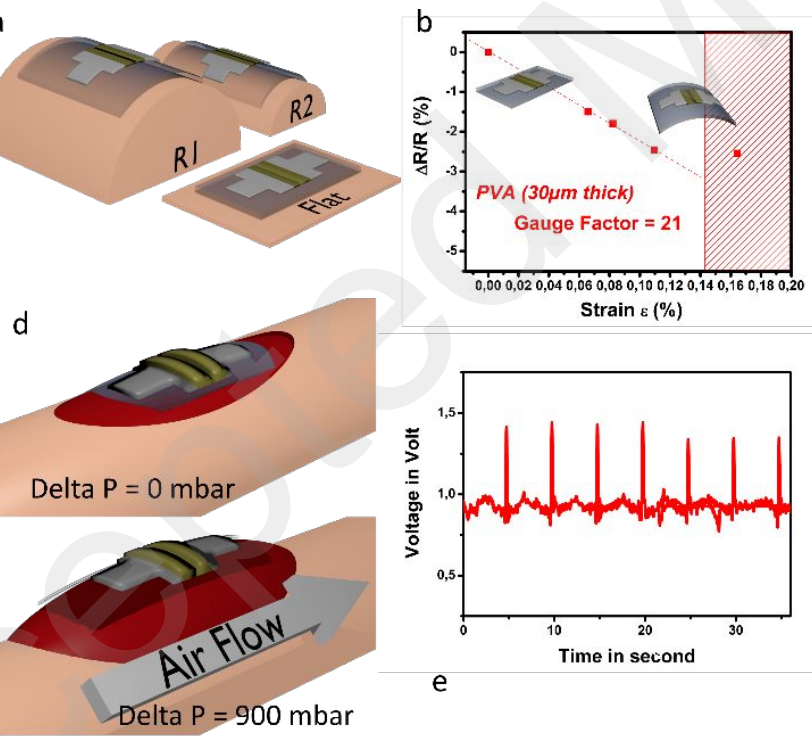

Strain $\varepsilon(\%)$

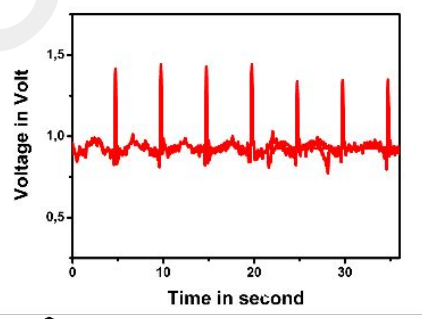

e fime in second f

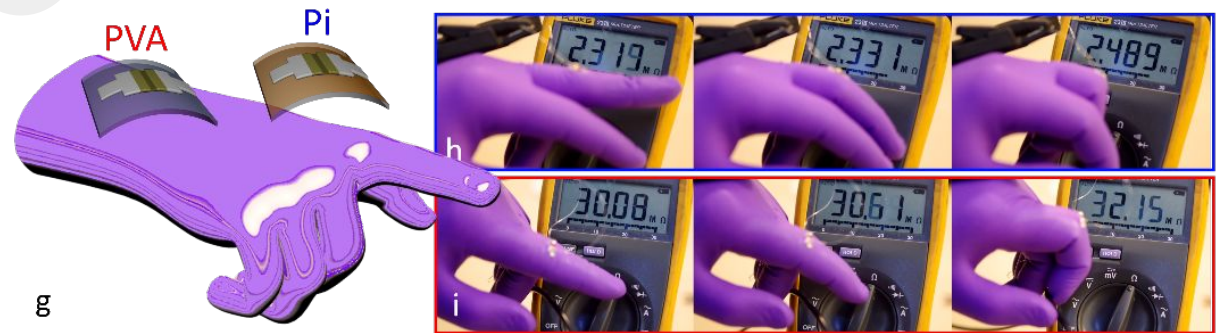

Strain $\varepsilon(\%)$
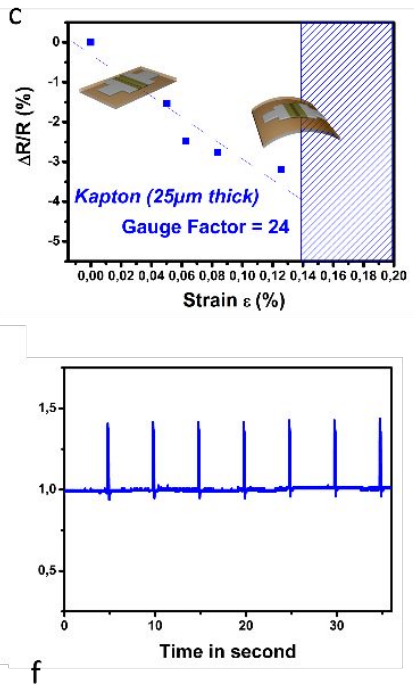
Figure 2: Mechanical behavior of inorganic strain sensor fabricated onto PVA and

Polyimide. a) 3D view of the measurement protocol in static operating mode. For both technologies (PVA and $\mathrm{Pi}$ ), the current versus the voltage is measured varying the radius of curvature (flat, $5 \mathrm{~cm}, 2 \mathrm{~cm}, 1.5 \mathrm{~cm}$ and $1 \mathrm{~cm}$ ); The variation of the resistivity as function of applied strain for strain sensors fabricated onto: b) PI substrate and c) PVA substrate. d) 3D view of the measurement protocol in dynamic operating mode; The strain sensors is mounted onto a rubber membrane deformed by a differential of pressure (900mbar); For both technologies (PVA and $\mathrm{Pi}$ ) response of voltage versus time at two different differential pressures ( 0 and $900 \mathrm{mbar}$ ) for strain sensors fabricated onto : e) PI substrate and f) PVA substrate. g) 3D view of strain sensors (PVA and PI substrates) mounted onto a nitrile glove. Resistivity response varying the finger bending angle for sensors fabricated onto: h) the PVA substrate and i) the PI substrate. 

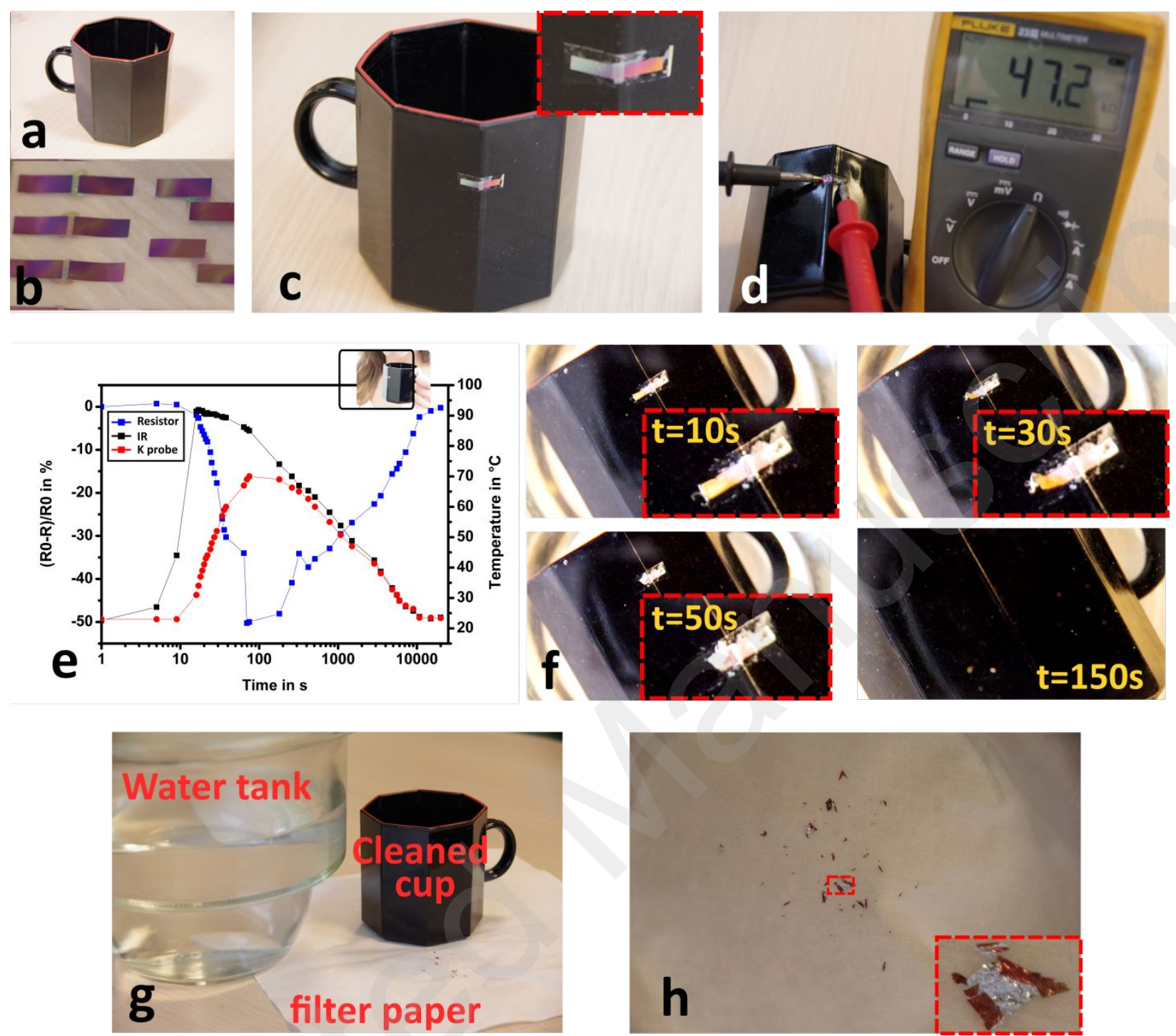

Figure 3: Ecodesigned inorganic sensor fabricated onto PVA: dissolution, transfer, dismantling and recovery. a) a cup as daily life object; b) resistor as temperature sensors fabricated onto PVA; c) water assisted transfer of the temperature sensors onto the cup. The inset highlights the inorganic device wraps onto a edge of the cup (angle $\left.=155^{\circ}\right)$; ) electrical test of the resistor; e) Evolution of: i) the sensor resistivity as function of the cup 


\begin{abstract}
temperature (blue curves, left axe), ii) k-probe thermocouple (red curve, right axe), iii) IR thermometer (black curve, right axe); f) dismantling of the inorganic device from the cup: g) The cup after dismantling the inorganic devices; $h$ ) inorganic films after filtration. The inset highlights metal and silicon.
\end{abstract}




\section{ASSOCIATED CONTENT:}

Supporting information:

Table S1: Mechanical characteristics of inorganic material that constitute the strain

sensor

Figure S1: Optical picture of cracks in silicon thin films due to an excess of strain.

Figure S2: Setup used to deform and acquire the strain sensor electrical signal.

\section{AUTHOR INFORMATION}

\section{Corresponding Author}

Dr. M. Harnois, 
Université Rennes 1, Institut d'Électronique et des Télécommunications de Rennes,

UMR CNRS 6164, Département Microélectronique \& Microcapteurs, Campus de

Beaulieu, 35042 Rennes Cedex, France.

E-mail : maxime.harnois@univ-rennes1.fr

\section{Author Contributions}

The manuscript was written through contributions of all authors. All authors have given approval to the final version of the manuscript.

\section{ACKNOWLEDGMENT}

This work is supported by the European Union through the European Regional

Development Fund (ERDF), by the French region of Brittany (project: IMPRIM'), and by IETR (project: 3DELEC). 
References

(1) Bohn, J.; Coroamă, V.; Langheinrich, M.; Mattern, F.; Rohs, M. Living in a World of Smart Everyday Objects-Social, Economic, and Ethical Implications. Hum. Ecol. Risk Assess. 2004, 10 (5), 763-785.

(2) Kibert, N. C. Extended Producer Responsibility: A Tool for Achieving Sustainable Development. J. Land Use Environ. Law 2004, 19 (2), 503-523.

(3) Goodship, V.; Stevels, A. Waste Electrical and Electronic Equipment (WEEE) Handbook, Elsevier, 2012.

(4) Ongondo, F. O.; Williams, I. D.; Cherrett, T. J. How Are WEEE Doing? A Global Review of the Management of Electrical and Electronic Wastes. Waste Manag. 2011, $31(4), 714-730$.

(5) Khosla, A.; Ahmed, K.; Shiblee, M. N. I.; Thundat, T.; Nagahara, L. A.; Furukawa, H. Shape Conformable Flexible Sensors for Internet of Things (IoT): A Perspective. In Meeting Abstracts; The Electrochemical Society, 2018; pp 284-284.

(6) Le Borgne, B.; De Sagazan, O.; Crand, S.; Jacques, E.; Harnois, M. Conformal Electronics Wrapped Around Daily Life Objects Using an Original Method: Water Transfer Printing. ACS Appl. Mater. Interfaces 2017, 9 (35), 29424-29429.

(7) Zhang, Z.; Cui, L.; Shi, X.; Tian, X.; Wang, D.; Gu, C.; Chen, E.; Cheng, X.; Xu, Y.; Hu, Y.; J. Zhang; L. Zhou; H.H. Fong; P. Ma; G. Jiang; X. Sun; B. Zhang; H. Peng; Textile Display for Electronic and Brain-Interfaced Communications. Adv. Mater. 2018, 30 (18), 1800323.

(8) Sekitani, T.; Nakajima, H.; Maeda, H.; Fukushima, T.; Aida, T.; Hata, K.; Someya, T. Stretchable Active-Matrix Organic Light-Emitting Diode Display Using Printable Elastic Conductors. Nat. Mater. 2009, $8(6)$,

(9) Kaltenbrunner, M.; White, M. S.; Głowacki, E. D.; Sekitani, T.; Someya, T.; Sariciftci, N. S.; Bauer, S. Ultrathin and Lightweight Organic Solar Cells with High Flexibility. Nat. Commun. 2012, 3, 770. 
(10) Peng, X.; Yuan, J.; Shen, S.; Gao, M.; Chesman, A. S.; Yin, H.; Cheng, J.; Zhang, Q.; Angmo, D. Perovskite and Organic Solar Cells Fabricated by Inkjet Printing: Progress and Prospects. Adv. Funct. Mater. 2017, 27 (41), 1703704.

(11) Adams, J. J.; Duoss, E. B.; Malkowski, T. F.; Motala, M. J.; Ahn, B. Y.; Nuzzo, R. G.; Bernhard, J. T.; Lewis, J. A. Conformal Printing of Electrically Small Antennas on Three-Dimensional Surfaces. Adv. Mater. 2011, 23(11), 1335-1340.

(12) Kraus, J. D.; Marhefka, R. J. Antennas for All Applications. Antennas Appl. Kraus John Daniel Marhefka Ronald J N. Y. McGraw-Hill C2002 2002.

(13) Salvatore, G. A.; Münzenrieder, N.; Kinkeldei, T.; Petti, L.; Zysset, C.; Strebel, I.; Büthe, L.; Tröster, G. Wafer-Scale Design of Lightweight and Transparent Electronics That Wraps around Hairs. Nat. Commun. 2014, 5, 2982.

(14) Rogers, J. A.; Someya, T.; Huang, Y. Materials and Mechanics for Stretchable Electronics. Science 2010, 327 (5973), 1603-1607.

(15) Zhang, Y.; Xu, S.; Fu, H.; Lee, J.; Su, J.; Hwang, K.-C.; Rogers, J. A.; Huang, Y. Buckling in Serpentine Microstructures and Applications in Elastomer-Supported Ultra-Stretchable Electronics with High Areal Coverage. Soft Matter 2013, 9 (33), 8062.

(16) Kim, D.-H.; Lu, N.; Ma, R.; Kim, Y.-S.; Kim, R.-H.; Wang, S.; Wu, J.; Won, S. M.; Tao, H.; Islam, A.; Yu, K. J.; Kim, T-I; Chowdhury, R.; Ying, M.; Xu, L.; Li M.; Chung, H. J.; Keum, H.; McCormick, M.; Liu, P.; Zhang, Y-W; Omenetto, F. G.; Huan, Y.; Coleman, T.; Rogers, J. A. Epidermal Electronics. science 2011, 333 (6044), 838843.

(17) Rogel, R.; Borgne, B. L.; Mohammed-Brahim, T.; Jacques, E.; Harnois, M. Spontaneous Buckling of Multiaxially Flexible and Stretchable Interconnects Using PDMS/Fibrous Composite Substrates. Adv. Mater. Interfaces 2017, 4(3), 1600946.

(18) Yang, Y.; Vervust, T.; Dunphy, S.; Van Put, S.; Vandecasteele, B.; Dhaenens, K.; Degrendele, L.; Mader, L.; De Vriese, L.; Martens, T.; Kaufmann, M.; Sekitani, T.; Vanfleteren, J.. 3D Multifunctional Composites Based on Large-Area Stretchable Circuit with Thermoforming Technology. Adv. Electron. Mater. 2018, 1800071.

(19) Irimia-Vladu, M. "Green" Electronics: Biodegradable and Biocompatible Materials and Devices for Sustainable Future. Chem. Soc. Rev. 2014, 43 (2), 588-610. 
(20) Irimia-Vladu, M.; Glowacki, E. D.; Voss, G.; Bauer, S.; Sariciftci, N. S. Green and Biodegradable Electronics. Mater. Today 2012, 15 (7-8), 340-346.

(21) Le Borgne, B.; Chung, B.-Y.; Tas, M. O.; King, S. G.; Harnois, M.; Sporea, R. A. Eco-Friendly Materials for Daily-Life Inexpensive Printed Passive Devices: Towards "Do-It-Yourself" Electronics. Electronics 2019, 8 (6), 699.

(22) Moorthy, B.; Baek, C.; Wang, J. E.; Jeong, C. K.; Moon, S.; Park, K.-I.; Kim, D. K. Piezoelectric Energy Harvesting from a PMN-PT Single Nanowire. RSC Adv. 2017, $7(1), 260-265$.

(23) Zhang, Y.; Sun, H.; Jeong, C. K. Biomimetic Porifera Skeletal Structure of LeadFree Piezocomposite Energy Harvesters. ACS Appl. Mater. Interfaces 2018, 10 (41), 35539-35546.

(24) Li, R.; Wang, L.; Kong, D.; Yin, L. Recent Progress on Biodegradable Materials and Transient Electronics. Bioact. Mater. 2018, 3 (3), 322-333.

(25) Fodil, K.; Denoual, M.; Dolabdjian, C.; Harnois, M.; Senez, V. Dynamic Sensing of Magnetic Nanoparticles in Microchannel Using GMI Technology. IEEE Trans. Magn. 2012, 49(1), 93-96.

(26) Yang, S.; Lu, N. Gauge Factor and Stretchability of Silicon-on-Polymer Strain Gauges. Sensors 2013, 13 (7), 8577-8594.

(27) French, P.; Evans, A. Piezoresistance in Polysilicon and Its Applications to Strain Gauges. Solid-State Electron. 1989, 32 (1), 1-10.

(28) Gleskova, H.; Wagner, S.; Soboyejo, W.; Suo, Z. Electrical Response of Amorphous Silicon Thin-Film Transistors under Mechanical Strain. J. Appl. Phys. 2002, 92 (10), 6224-6229.

(29) Kervran, Y.; De Sagazan, O.; Crand, S.; Coulon, N.; Mohammed-Brahim, T.; Brel, O. Microcrystalline Silicon: Strain Gauge and Sensor Arrays on Flexible Substrate for the Measurement of High Deformations. Sens. Actuators Phys. 2015, 236, $273-$ 280.

(30) Faurie, D.; Renault, P.-O.; Le Bourhis, E.; Villain, P.; Goudeau, P.; Badawi, F. Measurement of Thin Film Elastic Constants by X-Ray Diffraction. Thin Solid Films 2004, 469, 201-205. 
(31) Kaltenbrunner, M.; Sekitani, T.; Reeder, J.; Yokota, T.; Kuribara, K.; Tokuhara, T.; Drack, M.; Schwödiauer, R.; Graz, I.; Bauer-Gogonea, S.; Bauer, S.; Someya, T. An Ultra-Lightweight Design for Imperceptible Plastic Electronics. Nature 2013, 499 (7459), 458-463.

(32) Chortos, A.; Liu, J.; Bao, Z. Pursuing Prosthetic Electronic Skin. Nat. Mater. 2016, $15(9), 937$.

(33) Yang, S.; Chen, Y.-C.; Nicolini, L.; Pasupathy, P.; Sacks, J.; Su, B.; Yang, R.; Sanchez, D.; Chang, Y.-F.; Wang, P.; Schnyer, D.; Neikirk, D.; Lu, N. "Cut-andPaste" Manufacture of Multiparametric Epidermal Sensor Systems. Adv. Mater. 2015, 27 (41), 6423-6430.

(34) Martinho, G.; Pires, A.; Saraiva, L.; Ribeiro, R. Composition of Plastics from Waste Electrical and Electronic Equipment (WEEE) by Direct Sampling. Waste Manag. 2012, 32 (6), 1213-1217.

(35) Wang, Y.; Qiu, Y.; Ameri, S. K.; Jang, H.; Dai, Z.; Huang, Y.; Lu, N. Low-Cost, MmThick, Tape-Free Electronic Tattoo Sensors with Minimized Motion and Sweat Artifacts. Npj Flex. Electron. 2018, 2 (1), 6.

(36) Kabiri Ameri, S.; Ho, R.; Jang, H.; Tao, L.; Wang, Y.; Wang, L.; Schnyer, D. M.; Akinwande, D.; Lu, N. Graphene Electronic Tattoo Sensors. ACS Nano 2017, 11 (8), 7634-7641.

(37) Kim, D.-H.; Viventi, J.; Amsden, J. J.; Xiao, J.; Vigeland, L.; Kim, Y.-S.; Blanco, J. A.; Panilaitis, B.; Frechette, E. S.; Contreras, D.; Kaplan, D. L.; Omenetto F. G.; Huang Y.; Hwang, K. C.; Zakin, M. R.; Litt, B.; Rogers, J. A. Dissolvable Films of Silk Fibroin for Ultrathin Conformal Bio-Integrated Electronics. Nat. Mater. 2010, 9 (6), 511-517.

(38) Le Borgne, B.; Jacques, E.; Harnois, M. The Use of a Water Soluble Flexible Substrate to Embed Electronics in Additively Manufactured Objects: From Tattoo to Water Transfer Printed Electronics. Micromachines 2018, 9(9), 474.

(39) Ng, L. W.; Zhu, X.; Hu, G.; Macadam, N.; Um, D.; Wu, T.-C.; Moal, F. L.; Jones, C. G.; Hasan, T. Conformal Printing of Graphene for Single and Multi-Layered Devices on to Arbitrarily Shaped 3D Surfaces. ArXiv Prepr. ArXiv181101073 2018. 
(40) Saada, G.; Layani, M.; Chernevousky, A.; Magdassi, S. Hydroprinting Conductive Patterns onto 3D Structures. Adv. Mater. Technol. 2017, 2 (5), 1600289.

(41) Le Borgne, B.; Liu, S.; Morvan, X.; Crand, S.; Sporea, R. A.; Lu, N.; Harnois, M. Water Transfer Printing Enhanced by Water-Induced Pattern Expansion: Toward Large-Area 3D Electronics. Adv. Mater. Technol. 2019, 1800600.

(42) Tao, H.; Brenckle, M. A.; Yang, M.; Zhang, J.; Liu, M.; Siebert, S. M.; Averitt, R. D.; Mannoor, M. S.; McAlpine, M. C.; Rogers, J. A.; Kaplan, D. A.; Omenetto, F. G. Silk-Based Conformal, Adhesive, Edible Food Sensors. Adv. Mater. 2012, 24 (8), 1067-1072.

(43) Hwang, S.-W.; Park, G.; Edwards, C.; Corbin, E. A.; Kang, S.-K.; Cheng, H.; Song, J.-K.; Kim, J.-H.; Yu, S.; Ng, J.; Lee, J. E.; Kim, J.; Yee, C.; Bhaduri, B.; Su, Y.; Omenetto, F.G.;; Huang, Y; Bashir, R.; Goddard, L.; Popescu, G.; Lee, K.M.; Rogers, J. A. Dissolution Chemistry and Biocompatibility of Single-Crystalline Silicon Nanomembranes and Associated Materials for Transient Electronics. ACS Nano 2014, 8 (6), 5843-5851.

(44) Kang, S.-K.; Hwang, S.-W.; Cheng, H.; Yu, S.; Kim, B. H.; Kim, J.-H.; Huang, Y.; Rogers, J. A. Dissolution Behaviors and Applications of Silicon Oxides and Nitrides in Transient Electronics. Adv. Funct. Mater. 2014, 24 (28), 4427-4434.

ToC figure 


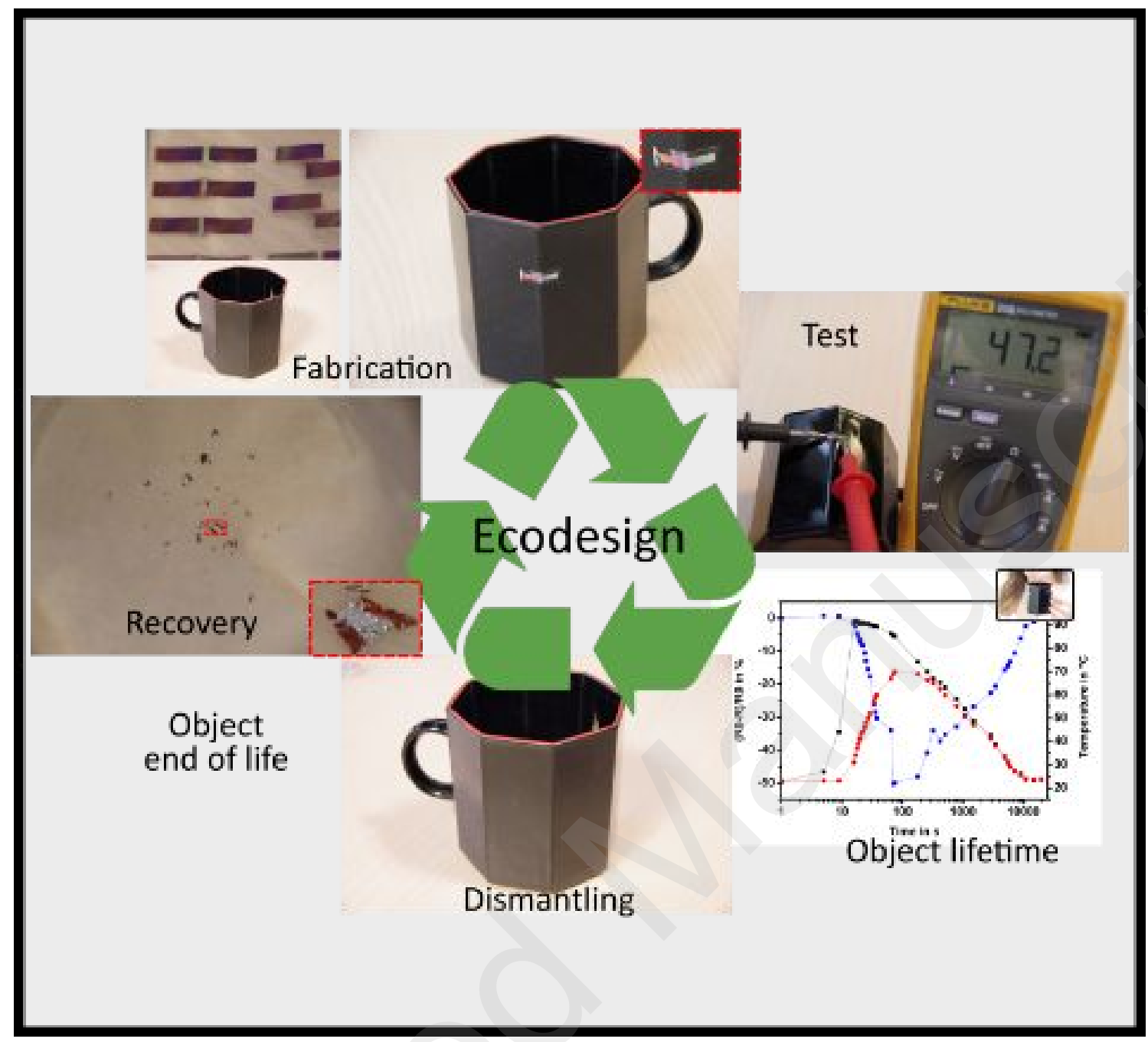







a

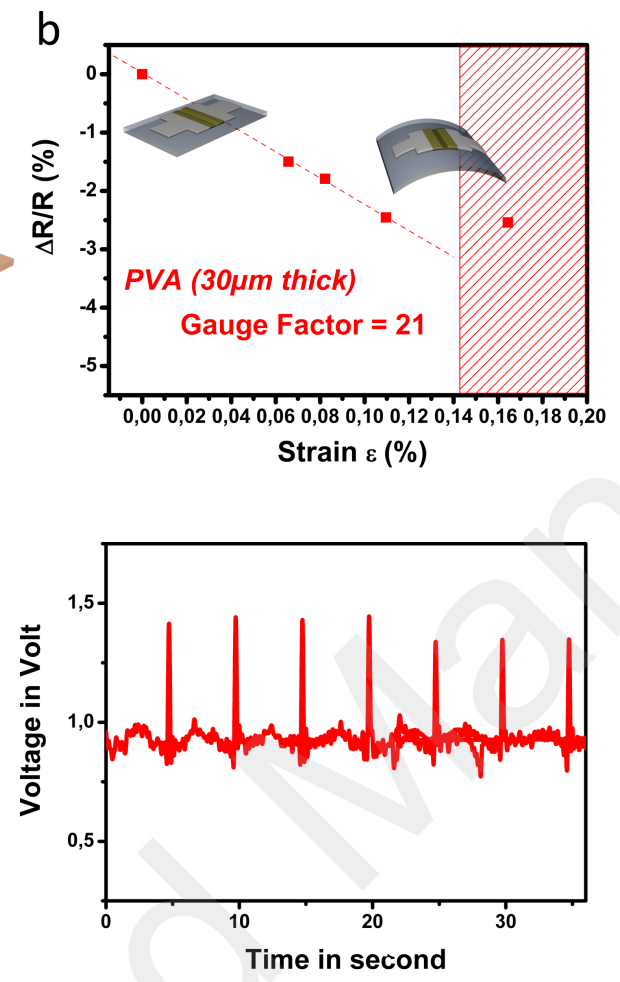

e
C
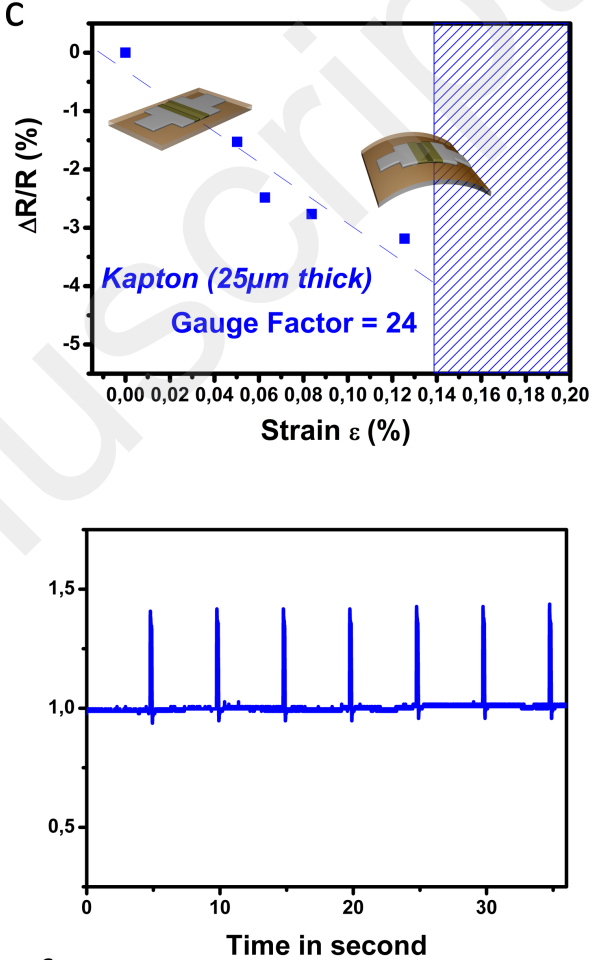

f

Strain $\varepsilon(\%)$

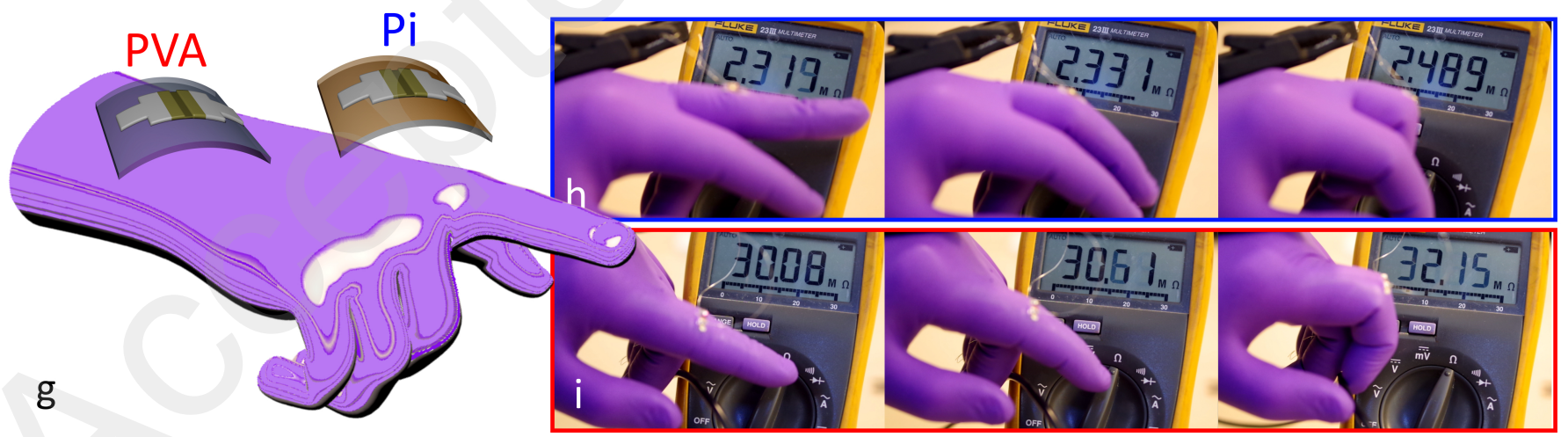



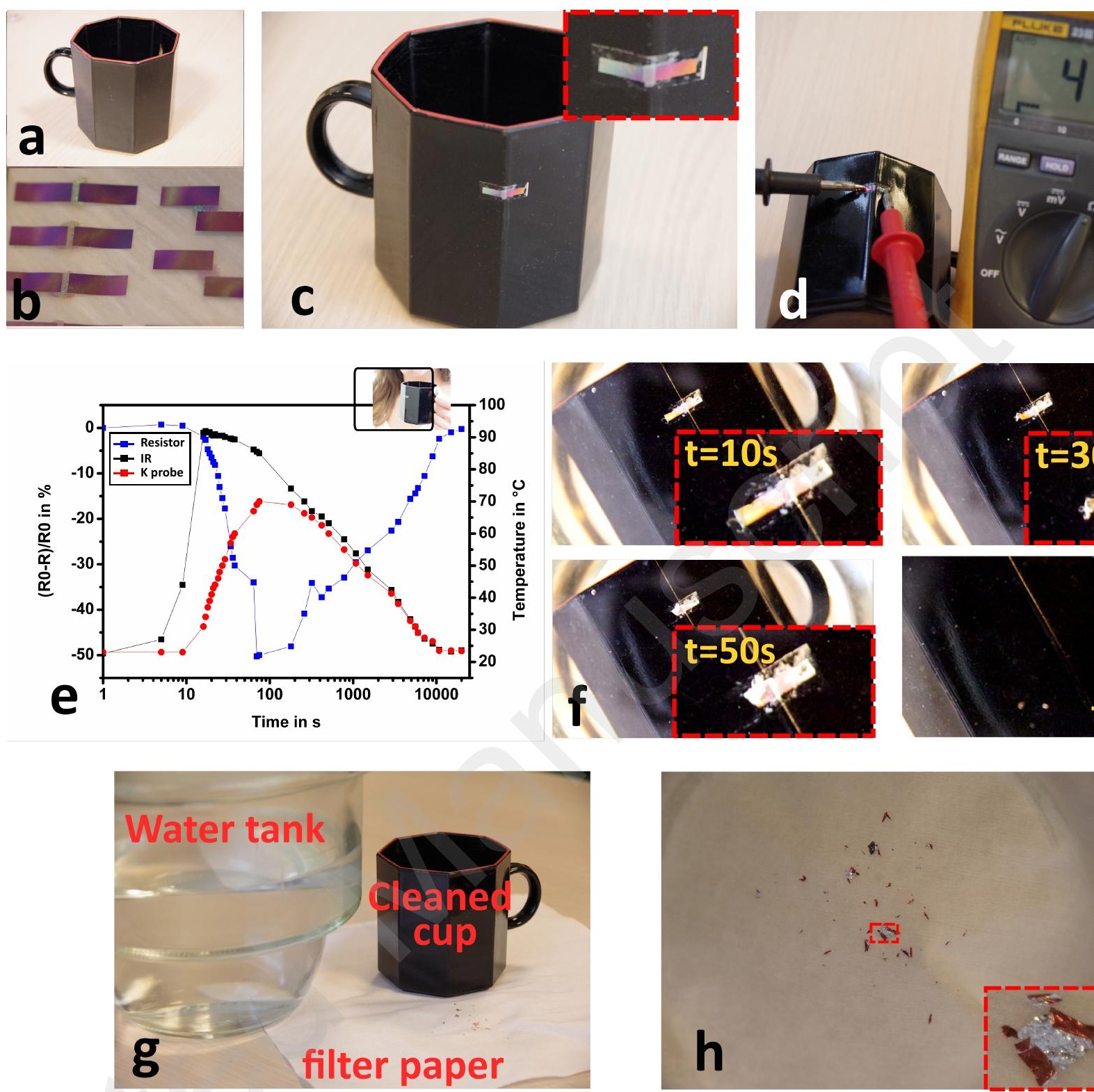


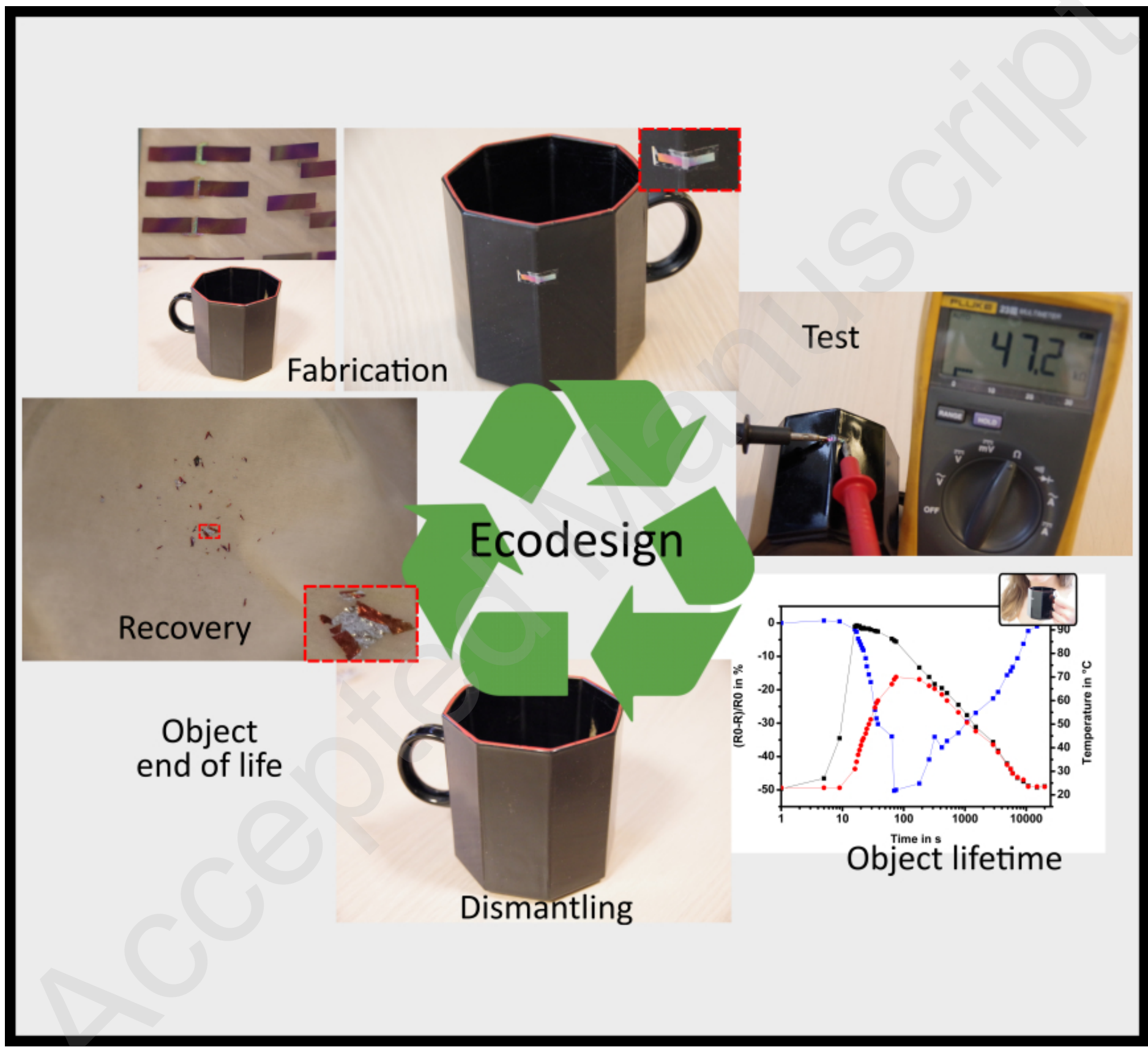

